Die Beurtheilung der Resultate von Chocolade-Analysen basirt R. Bensemann*) auf das Verbältniss von wasserunlöslichen organischen Körpern, Fett und Stärke zu einander. Da die Arbeit sich auf Berechnungen beschränkt und neue analytische Methoden nicht gibt, so begnüge ich mich, dieselbe hier zu erwähnen.

Ahornzucker. Nach Untersuchungen von H. W. Wiley**) enthält Ahornsaft keine Spur direct reducirenden Zuckers. 28 Analysen von frischem Safte ergaben im Mittel einen Zuckergehalt von 2,82\% (Maximum 4,30, Minimum 1,87\%). Bei der Bereitung des Ahornzuckers bildet sich nur verhältnissmässig wenig Invertzucker. In sechs unverfälschten Melassen schwankte der Gehalt an Rohrzucker zwischen 39,22 und $64,45 \%$, derjenige an reducirendem Zucker zwischen 0,21 und $3,24 \%$; der Wassergehalt betrug über $30 \%$. Im Ahornzucker selbst fand Verfasser $7,59-10,75 \%$ Wasser, $0,80-5 \%$ Invertzucker und ziemlich constant etwa $84 \%$ Rohrzucker.

Die Veraschung von Rohzuckern führt Li p p man $\left.\mathrm{n}^{* * *}\right)$ ans, indem er den Rohzucker in einer Platinschale oder einem Porzellantiegel trocknet, mit so viel Vaselinöl begiesst, dass der Zucker reichlich und gleichmässig durchfeuchtet ist, und nun langsam erhitzt. Der Zucker wird allmählich dunkler, bildet eine blasige Masse, verkohlt ohne heftiges Aufschwellen and ohne Gasentwicklung, indem er sich schliesslich entzündet, und hinterlässt eine Kohle, deren Volum kaum grösser als das der Substanz ist und die sich meist leicht aus der Schale entfernen und leicht verbrennen lässt. Selbst bei $10-20 \mathrm{~g}$ Zucker gelingt die Verkohlung leicht. Zur Bestimmung des löslichen Antheils der Asche kann man die Kohle im Extractionsapparate ausziehen.

\title{
Die Verwendung des Volumenometers bei der Untersuchung
} von Nahrungsmitteln, Genussmitteln und Gebrauchsgegenständen hat Wilh. Thörner †) versucht. Ich verfehle nicht auf diese Arbeit aufmerksam zu machen, da abzuwarten bleibt, ob die Resultate derselben sich praktisch werden verwerthen lassen.

*) Ber. d. deutsch. chem. Gesellsch. zu Berlin 16, 856. Vergleiche auch Bensemann's ergänzende Mittheilungen, Repert. f. analyt. Chemie 4, 213 und $5,178$.

**) Chem. News 51, 88. Chemiker-Zeitung 9, 645.

***) Zeitschr. d. Vereins f. Zucker-Ind. 34, 646 .

$\dagger$ ) Repert. f. analyt. Chemie 5, 25. 